\title{
COX-1 and COX-2 Contributions to Basal and IL-1 $\beta$-Stimulated Prostanoid Synthesis in Human Neonatal Cerebral Microvascular Endothelial Cells
}

\author{
HELENA PARFENOVA, VLADIMIR LEVINE, WENDY M. GUNTHER, \\ MASSROOR POURCYROUS, AND CHARLES W. LEFFLER \\ Laboratory for Research in Neonatal Physiology, Departments of Physiology [H.P., M.P., C.W.L.], \\ Pediatrics, and Obstetrics and Gynecology [V.L., W.M.G., M.P., C.W.L.], Vascular Biology Center, \\ University of Tennessee Health Science Center, Memphis, Tennessee 38163, U.S.A.
}

\begin{abstract}
Mechanisms of endothelium-dependent regulation of cerebral circulation in human neonates are poorly understood owing to the lack of experimental data. Prostanoids, the products of the cyclooxygenase (COX) pathway, appear to be important regulators of blood flow in neonates. COX activity in cultured endothelial cells from small $(60-300 \mu \mathrm{m})$ and large $(>300 \mu \mathrm{m})$ microvessels from the autopsy specimens of neonatal human cerebral cortex and cerebellum (22-26 wk gestational age) was detected as production of vasodilator prostanoids, prostacyclin [as 6-keto-prostaglandin (PG) $\mathrm{F}_{1 \alpha}$ ] and $\mathrm{PGE}_{2}$ from arachidonic acid. Treatment of neonatal human cerebral microvascular endothelial cells (hCMVEC) with IL-1 $\beta(50 \mathrm{ng} / \mathrm{mL}, 17 \mathrm{~h})$ stimulated COX activity 5 - to 20 -fold. Basal and IL- $1 \beta$-stimulated COX activities were inhibited by NS-398, indicating substantial COX-2 contribution to endothelial prostanoid synthesis in neonatal human brain cortex and cerebellum at rest and when mimicking the inflammatory conditions. Increased COX-2linked activity in response to IL- $1 \beta$ was observed in hCMVEC from both cerebrum and cerebellum (5- to 20-fold), while under the same conditions elevated COX-1-linked activity was detected only in hCMVEC from cerebellum (5- to 10-fold). In
\end{abstract}

\section{ABSTRACT}

IL-1 $\beta$-treated hCMVEC, a shift toward $\mathrm{PGE}_{2}$ as the major vasodilator product of the COX pathway was observed. Acute treatment with the protein tyrosine kinase inhibitor, tyrphostin 25 , inhibited basal and IL- $1 \beta$-induced COX activities, suggesting the importance of posttranslational modifications in endothelial COX-2 activation in human brain. Altogether, these data indicate that both COX-1 and COX-2 contribute to endothelial prostanoid synthesis in the neonatal human brain under basal conditions and in response to proinflammatory cytokine IL- $1 \beta$.

(Pediatr Res 52: 342-348, 2002)

Abbreviations
COX, cyclooxygenase
CMVEC, cerebral microvascular endothelial cells
hCMVEC, human cerebral microvascular endothelial cells
pCMVEC, piglet cerebral microvascular endothelial cells
PTK, protein tyrosine kinase
NO, nitric oxide
PG, prostaglandin

Cerebral circulatory disorders produce serious complications in human neonates, such as cerebral hemorrhages and hypoxicischemic injuries, that can result in life-long neurologic dysfunction in survivors including cerebral palsy, epilepsy, and mental retardation. Mechanisms of the regulation of cerebral circulation in neonates are understood incompletely, and experimental data are very limited. Vascular endothelium-derived dilator prostanoids, NO, and carbon monoxide are vasorelaxant factors essential in the regulation of cerebral blood flow. There are species-

Received July 23, 2001; accepted March 22, 2002.

Correspondence and reprint requests: Helena Parfenova, Ph.D., Department of Physiology, University of Tennessee Health Science Center, 894 Union Avenue, Memphis, TN 38163, U.S.A.; e-mail: hparf@physiol.utmem.edu

Supported by NHLBI/NIH and the Southeast Affiliate of the American Heart Association.

DOI: 10.1203/01.PDR.0000025344.66006.C5 specific and age-dependent differences in physiologically relevant endothelial vasorelaxants in the cerebral circulation (1). In human newborns, prostanoids appear to be major factors that contribute to regulation of cerebral blood flow in response to hypercapnia, asphyxia, ischemia, and cerebral hemorrhage (1-3), and indomethacin is widely used in neonatal practice $(2,4,5)$. Similarly, in newborn pigs, prostanoids contribute to the regulation of cerebral blood flow under basal conditions and in response to physiologically important stimuli, such as $\mathrm{CO}_{2}$, oxygen, and changes in blood pressure (1). Prostanoids are also important in the pathogenesis of inflammation because they alter interactions between blood cells, platelets, and the vascular wall, and are important players in the inflammatory response (6).

$\mathrm{COX}$, a rate-limiting enzyme in prostanoid synthesis, is represented by two distinct gene products, COX-1 and COX-2. 
COX-1 appears to be maximally expressed under basal conditions, whereas COX-2 is usually induced by inflammatory agents and mitogens (6). However, in vivo and in vitro studies in piglets demonstrated that COX-2 also functions in the cerebral vasculature of newborn pigs under basal nonstimulated conditions, thus potentially contributing to cerebral hemodynamics (7-11). COX-1 and COX-2 proteins were also detected by Western immunoblotting and immunostaining in endothelial cells from neonatal human brain at early passages (10). These data indicate that COX-2 may be important in functioning of normal human fetal vessels, including cerebral microvessels. However, no data on contributions of COX-1 and COX-2 to endothelial prostanoid synthesis in human newborns are available. In the present study we addressed the hypothesis that COX-2 is a predominant functional COX isoform in neonatal hCMVEC under basal conditions and in responses to inflammatory mediators. Using indomethacin and NS-398, a COX-2 selective inhibitor, we investigated functional contributions of COX-1 and COX-2 to prostanoid synthesis in hCMVEC from two functionally distinct neonatal brain areas, cerebral cortex and cerebellum, under basal and stimulated conditions. Proinflammatory cytokine IL- $1 \beta$ that can up-regulate COX-2 mRNA and protein expression in endothelial cells (10) was selected as a tool to investigate stimulated COX responses in hCMVEC.

\section{METHODS}

Isolation of cerebral microvessels. Brain cortex was obtained from preterm human newborns ( $n=4$, gestational age, 22 and $26 \mathrm{wk}$; Table 1). Cause of death was cardiorespiratory or cardiovascular failure and other complications secondary to severe prematurity (Table 1). Postmortem collection of human brain tissue for these specific studies was approved by the Institutional Review Board. These patients were from the Regional Medical Center, Women Hospital and Perinatal Center, Memphis, TN, U.S.A. When an informed consent form for the autopsy was already signed by a parent, one of the collaborating investigators approached the parent and explained the purpose of this study and obtained a signature for a separate consent form for the study. The samples from cerebral cortex and cerebellum were collected by the pathologist at autopsy performed within $6-12 \mathrm{~h}$ of the infant's death. The samples were immediately transported to the laboratory on ice. Microvessels from human neonatal brain were isolated as described previously (7). The brain tissue samples (10-20 g) were gently homogenized in M199 media using a glass homogenizer with a loose fitting pestle and filtered through 300and $60-\mu \mathrm{m}$ nylon mesh screens consecutively. Large cerebral microvessels $(>300 \mu \mathrm{m})$ collected on the first screen, and small microvessels $(60-300 \mu \mathrm{m})$ collected on the last screen were used for Western immunoblotting or for isolation of endothelial cells.

Cerebrovascular endothelial cells in culture. To isolate endothelial cells, cerebral microvessels were treated with collagenase-dispase $\left(2 \mathrm{mg} / \mathrm{mL}\right.$ for $2 \mathrm{~h}$ at $\left.37^{\circ} \mathrm{C}\right)$, and dissociated hCMVEC were separated on a Percoll density gradient as described (10). Cells were plated on Matrigel-coated plates (3 $\times 10^{4}$ cells/well $)$ and cultured at $37^{\circ} \mathrm{C}\left(5 \% \mathrm{CO}_{2}-95 \%\right.$ air $)$. hCMVEC were cultured in the complete growth medium for hCMVEC (BioWhittaker, Inc., San Diego, CA, U.S.A.) containing 7\% FBS. All experiments were performed on confluent quiescent cells at one to two passages. Endothelial cells were maintained 4-7 d in each passage (total, $\leq 20 \mathrm{~d}$ from the collection). To achieve quiescence, hCMVEC were exposed to a serum-depleted medium $(0.1 \% \mathrm{FBS})$ for $15-20 \mathrm{~h}$ before the experiment.

Western blotting. Cerebral microvessels were lysed in the Laemmli buffer $(0.125 \mathrm{mM}$ TrisHCl, $\mathrm{pH} 6.8$, containing $10 \%$ glycerol, $2.5 \%$ SDS, $0.006 \%$ bromphenol blue, and $0.1 \mathrm{M}$ dithiothreitol) for $10 \mathrm{~min}$ at $100^{\circ} \mathrm{C}(10)$. Each sample was processed immediately after collection, and the sample collection was extended over a period of 6 mo because of difficulties with selecting deceased neonates for the study. Proteins (30 $\mu \mathrm{g}$ protein/lane) were separated by $7.5 \%$ SDS-PAGE and transferred to nitrocellulose membranes. The membranes were blocked for $1 \mathrm{~h}$ with $5 \%$ BSA buffer solution containing $0.1 \%$ Tween-20. The membranes were probed with polyclonal antibody to COX-2 peptide of human origin (Cayman Systems, Stoneham, MA, U.S.A., at 1:10,000 dilution), or polyclonal antibody to COX-1 peptide (Oxford Biomed, Oxford, MI, U.S.A., at 1:1,000 dilution), followed by peroxidaseconjugated donkey anti-rabbit IgG (Jackson Immunoresearch, West Grove, PA, U.S.A., at 1:10,000 dilution) (10). The immunoreactive bands were visualized with the Renaissance chemiluminescence kit (NEN Life Science Products, Boston, MA, U.S.A.) and quantified by digital densitometry using NIH Image 1.60 .

IL-1 $\boldsymbol{\beta}$ treatment. hCMVEC were incubated for $17 \mathrm{~h}$ with the starvation media $(0.1 \% \mathrm{FBS})$ alone (control) or with the starvation media containing human IL-1 $\beta(50 \mathrm{ng} / \mathrm{mL})(10)$. Based on our preliminary data, under these treatment conditions IL-1 $\beta$ most effectively increases prostanoid production without affecting endothelial cell viability. Cells were used for detection of COX activity as described below.

COX activity. COX activity in hCMVEC was detected as production of 6-keto- $\mathrm{PGF}_{1 \mathrm{a}}$ and $\mathrm{PGE}_{2}$ from exogenous $\mathrm{AA}$ (7).

Table 1. Characteristics of infants

\begin{tabular}{cccccccl}
\hline $\begin{array}{c}\text { Patient } \\
\text { number }\end{array}$ & $\begin{array}{c}\text { BW } \\
(\mathrm{g})\end{array}$ & $\begin{array}{c}\text { GA } \\
(\mathrm{wk})\end{array}$ & Sex & $\begin{array}{c}\text { Apgar score } \\
(1 \text { and } 5 \mathrm{~min})\end{array}$ & $\begin{array}{c}\text { Age at } \\
\text { death }(\mathrm{h})\end{array}$ & $\begin{array}{c}\text { IVH } \\
(\text { grade })\end{array}$ & Cause of death \\
\hline 1 & 890 & 26 & $\mathrm{M}$ & $6 / 7$ & 30 & B IV & Cardiorespiratory failure secondary to B IV \\
2 & 400 & 22 & $\mathrm{~F}$ & $3 / 4$ & 50 & B III & Severe prematurity, cardiorespiratory failure secondary to B III \\
3 & 410 & 22 & F & $3 / 5$ & 9 & R III & Severe prematurity, cardiorespiratory failure secondary to R III \\
4 & 740 & 26 & M & $4 / 6$ & 20 & No & Acute cardiovascular failure secondary to cardiac tamponade \\
\hline
\end{tabular}

Abbreviations used: BW, birth weight; GA, gestational age; IVH, intraventricular hemorrhage. 
Control or IL-1 $\beta$-treated cells were incubated with $30 \mu \mathrm{M}$ AA in Krebs' buffer (in mM: $5.0 \mathrm{KCl}, 0.6 \mathrm{MgSO}_{4}, 1.8 \mathrm{CaCl}_{2}, 120$ $\mathrm{NaCl}, 6.0$ glucose, 10.0 HEPES, pH 7.4) for $15 \mathrm{~min}$ at $37^{\circ} \mathrm{C}$. To investigate the contribution of COX-2, we incubated control or IL- $1 \beta$-pretreated cells with $10^{-5}$ M NS-398 for $20 \mathrm{~min}$ (7). To inhibit both COX-1 and COX-2, indomethacin $\left(10^{-5}\right.$ M) was added $20 \mathrm{~min}$ before the detection of the COX activity (7). To determine the effect of protein tyrosine phosphorylation, control or IL- $1 \beta$-pretreated cells were incubated with 300 $\mu \mathrm{M}$ tyrphostin 25 for $30 \mathrm{~min}$ immediately before the COX activity detection (7). All inhibitors were also included in the incubation media for COX activity detection. After incubation with AA, the media was aspirated for prostanoid detection, and the cells were lysed in $0.1 \mathrm{~N} \mathrm{HCl}$ for protein determination.

Prostanoid and protein assays. Concentrations of 6-keto$\mathrm{PGF}_{1 \alpha}$ (the stable hydrolysis product of prostacyclin) and $\mathrm{PGE}_{2}$ in the media were determined by RIA as described (7). The prostanoid concentration was normalized to the amount of total cell protein quantified by the micro BCA protein assay from Pierce (Rockford, IL, U.S.A.).

Data analysis. Data are presented as mean \pm SEM of absolute values. Data were analyzed by ANOVA for repeated measurements, followed by Fisher's exact test for protected least significant difference to isolate differences among groups. A level of $p<0.05$ was considered significant.

Materials. Cell culture reagents were purchased from Life Technologies (Gaithersburg, MD, U.S.A.) and Sigma Chemical Co. (St. Louis, MO, U.S.A.). Percoll was from Amersham Pharmacia Biotech (Piscataway, NJ, U.S.A.). Matrigel (growth factor reduced) was from Becton Dickinson (Bedford, MA, U.S.A.). Human recombinant IL- $1 \beta$ was obtained from R\&D Systems Inc. (Minneapolis, MN, U.S.A.). Tyrphostin 25 was from Biomol (Plymouth Meeting, PA, U.S.A.). NS-398 and AA (peroxide-free) were from Cayman Chemical (Ann Arbor, MI, U.S.A.). Indomethacin (sodium salt) was purchased from Merck (Rahway, NJ, U.S.A.).

\section{RESULTS}

COX-1 and COX-2 expression in cerebral microvessels from neonatal human brain. Using Western immunoblotting, we examined COX-1 and COX-2 expression in cerebral microvessels of human premature neonates. Our data demonstrate that both COX-1 and COX-2 were expressed in cerebral microvessels from three babies (gestational age, 22-26 wk; Fig. 1). The immunoprobing of each sample was conducted

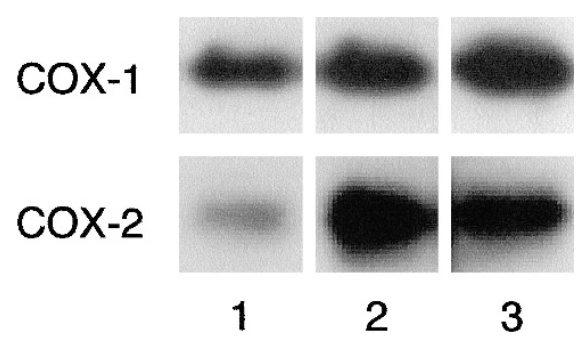

Figure 1. COX-1 and COX-2 detection by Western immunoblotting in small cerebral microvessels from human brain cortex (autopsies from patents 1, 2, and 3). separately because the sample collection was extended for a period of 6 mo. This may contribute to apparent variability of the COX-1 and COX-2 expression between the samples. As we found previously, COX-1 and COX-2 are also immunodetectable in cultured hCMVEC at quiescence (10).

COX activity in endothelial cells from neonatal human brain. We compared COX activity in hCMVEC isolated from large $(>300 \mu \mathrm{m})$ and small $(60-300 \mu \mathrm{m})$ microvessels from cerebral cortex and cerebellum. COX activity in these four groups of cells was detected under basal conditions and after prolonged treatment with human IL-1 $\beta$. hCMVEC exhibited COX activity as determined by production of two major vasodilator prostanoids, 6-keto-PGF ${ }_{1 \alpha}$ (the hydrolysis product of prostacyclin) and $\mathrm{PGE}_{2}$ (Fig. 2). Under basal conditions, no substantial differences in COX activity were found between endothelial cells from large and small microvessels, or between cerebral cortex and cerebellum: 6-keto- $\mathrm{PGF}_{1 \alpha}$ production from $30 \mu \mathrm{M}$ AA was $5-15 \mathrm{pg} / \mu \mathrm{g}$ protein, and $\mathrm{PGE}_{2}$ production was 15-30 pg/ $\mu$ g protein (Fig. 2). The basal $\mathrm{PGE}_{2}$ to 6-keto-PGF ${ }_{1 \alpha}$ ratio varied from $2: 1$ to $3: 1$. These characteristics of human neonatal brain endothelial COX are comparable to the COX activity in endothelial cells from the newborn pig brain (7). hCMVEC from large and small microvessels from cerebral cortex and cerebellum responded to human IL-1 $\beta(50 \mathrm{ng} / \mathrm{mL}$, $17 \mathrm{~h}$ ) with large increases in COX activity (Fig. 2). 6-keto-

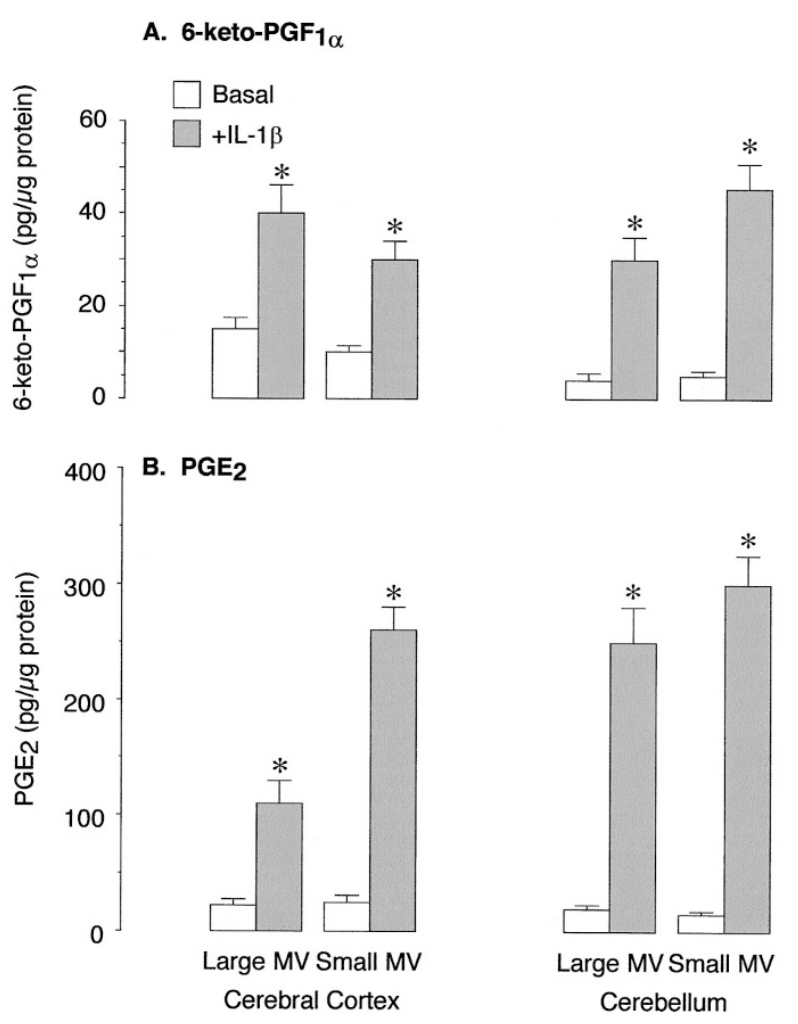

Figure 2. Basal and IL-1 $\beta$-stimulated COX activity in cultured endothelial cells from neonatal human brain. Quiescent endothelial cells from large microvessels (Large $M V$ ) and small microvessels (Small $M V$ ) from cerebral cortex and cerebellum (passage 1-2) were untreated (basal) or treated with 50 $\mathrm{ng} / \mathrm{mL}$ human IL-1 $\beta$ for $17 \mathrm{~h}$. COX activity was detected as production of 6-keto-PGF $\mathrm{PG}_{1 \alpha}(A)$ and $\mathrm{PGE}_{2}(B)$ from $30 \mu \mathrm{M}$ AA. The experiment was reproduced three times. Data are mean \pm SEM. ${ }^{*} p<0.05$ compared with the basal levels. 
$\mathrm{PGF}_{1 \alpha}$ production in IL-1 $\beta$-treated cells was elevated 3- to 6-fold, whereas $\mathrm{PGE}_{2}$ production was increased 5- to 20-fold (Fig. 2). As a result, $\mathrm{PGE}_{2}$ was the most prominent prostanoid produced by IL- $1 \beta$-treated hCMVEC ( $\mathrm{PGE}_{2}$ to 6 -keto-PGF $1 \alpha$ ratio varied from $5: 1$ to $10: 1, p<0.05)$, suggesting that specific terminal PG synthases could be differently upregulated in response to the proinflammatory agent. No differences in basal COX activity or in responses to IL- $1 \beta$ were observed between hCMVEC at first and second passages (data not shown).

Effects of indomethacin, NS-398, and tyrphostin 25 on basal COX activity. To investigate whether COX-2 contributes to endothelial prostanoid synthesis in neonatal hCMVEC under basal nonstimulated conditions, we used NS-398, the COX-2 selective inhibitor. Indomethacin was used as an effective nonselective inhibitor of COX-1 and COX-2 isoforms (7). Similar to our results in pCMVEC, indomethacin $\left(10^{-4} \mathrm{M}\right)$ inhibited 70 to $90 \%$ of basal COX activity in neonatal hCMVEC (Fig. 3). We have shown previously that NS-398 $\left(10^{-5}\right.$ $\left.10^{-4} \mathrm{M}\right)$ rapidly inhibits COX-2-directed activity in pCMVEC (7). Acute treatment with tyrphostin (100-300 $\mu \mathrm{M})$, a PTK inhibitor, inhibited COX-2, but not COX-1, activity in endothelial cells from newborn pigs (7). Therefore, we used tyrphostin 25 as an additional probe to assess COX-2-linked activity in neonatal hCMVEC. Cells were treated with NS-398 or tyrphostin 25 acutely $(30 \mathrm{~min})$ to ensure that COX expres-
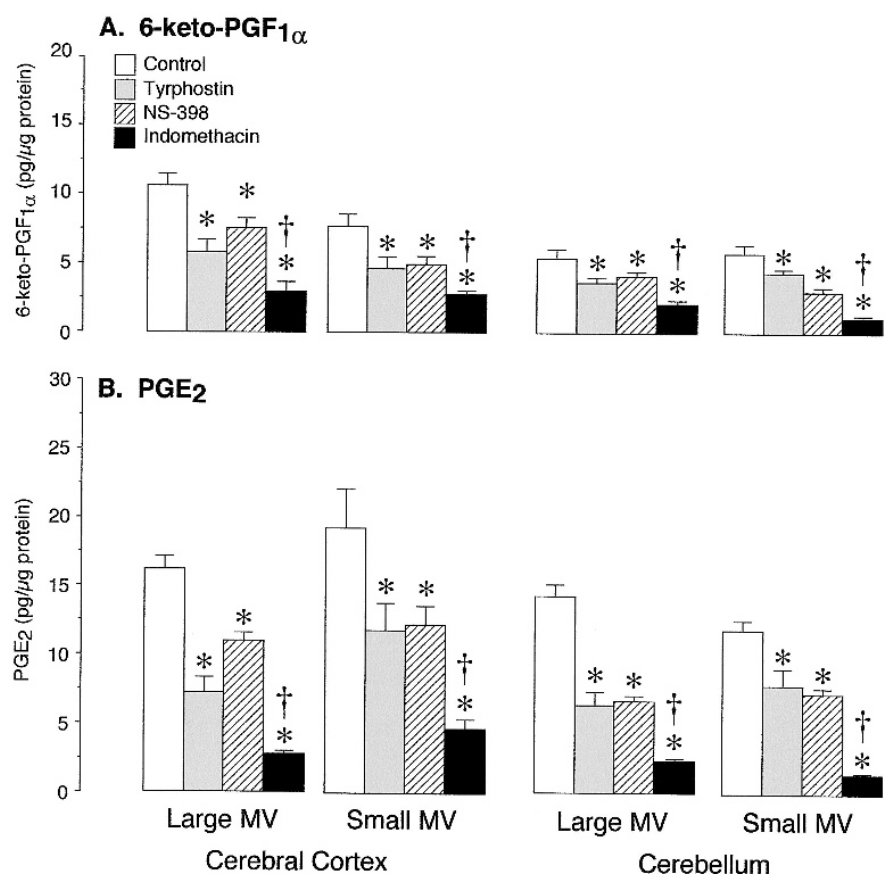

Figure 3. Effects of indomethacin, tyrphostin 25, and NS-398 on basal COX activity in endothelial cells from neonatal human brain. Quiescent endothelial cells from large microvessels (Large $M V$ ) and small microvessels (Small MV) from cerebral cortex and cerebellum (passage 1-2) were untreated (control) or treated with tyrphostin $25(300 \mu \mathrm{M}), \mathrm{NS}-398\left(10^{-4} \mathrm{M}\right)$, or indomethacin $\left(10^{-4}\right.$ M) for $30 \mathrm{~min}$; inhibitors were also included in the incubation medium for determination of COX activity. COX activity was detected as production of 6-keto-PGF ${ }_{1 \alpha}(A)$ and $\mathrm{PGE}_{2}(B)$ from $30 \mu \mathrm{M}$ AA. The experiment was reproduced three times. Data are mean \pm SEM. $* p<0.05$ compared with the control levels. $\dagger p<0.05$ compared with the NS-398 levels. sion was not altered (7). NS-398 inhibited 30 to $50 \%$ of total basal COX activity in hCMVEC from both large and small microvessels from cerebral cortex and cerebellum (Fig. 3). Tyrphostin 25 also decreased basal COX activity by 30 to $50 \%$ (Fig. 3). No regional or size-related differences were found in responses of hCMVEC to NS-398 or tyrphostin 25 (Fig. 3). These functional data suggest that during basal conditions, COX-2 accounts for up to $50 \%$ of total endothelial prostanoid synthesis in human neonatal brain. No differences were observed between first and second passages of hCMVEC in their responses to NS-398 or tyrphostin 25 (data not shown).

Effects of indomethacin, NS-398, and tyrphostin 25 on COX activity in IL-1 $\beta$-stimulated hCMVEC. To investigate contributions of COX-1 and COX-2 to prostanoid synthesis in IL- $\beta$-treated neonatal hCMVEC, we used acute $(30 \mathrm{~min})$ treatment with NS-398 $\left(10^{-5} \mathrm{M}\right)$ or tyrphostin $25(300 \mu \mathrm{M})$ to ensure that the inhibitors do not affect the COX protein induction. Indomethacin $\left(10^{-4} \mathrm{M}\right)$ inhibited $\geq 80 \%$ of the cytokinestimulated COX activity in hCMVEC from neonatal cerebral cortex and cerebellum. NS-398 inhibited 50 to $90 \%$ of IL- $1 \beta$ stimulated COX activity (both 6-keto- $\mathrm{PGF}_{1 \alpha}$ and $\mathrm{PGE}_{2}$ production; Fig. 4), indicating major contribution of COX-2 to prostanoid synthesis in activated hCMVEC. Tyrphostin 25 also inhibited 50 to $80 \%$ of COX activity in IL- $1 \beta$-treated hCMVEC (Fig. 4). These functional data indicate that in IL- $1 \beta-$
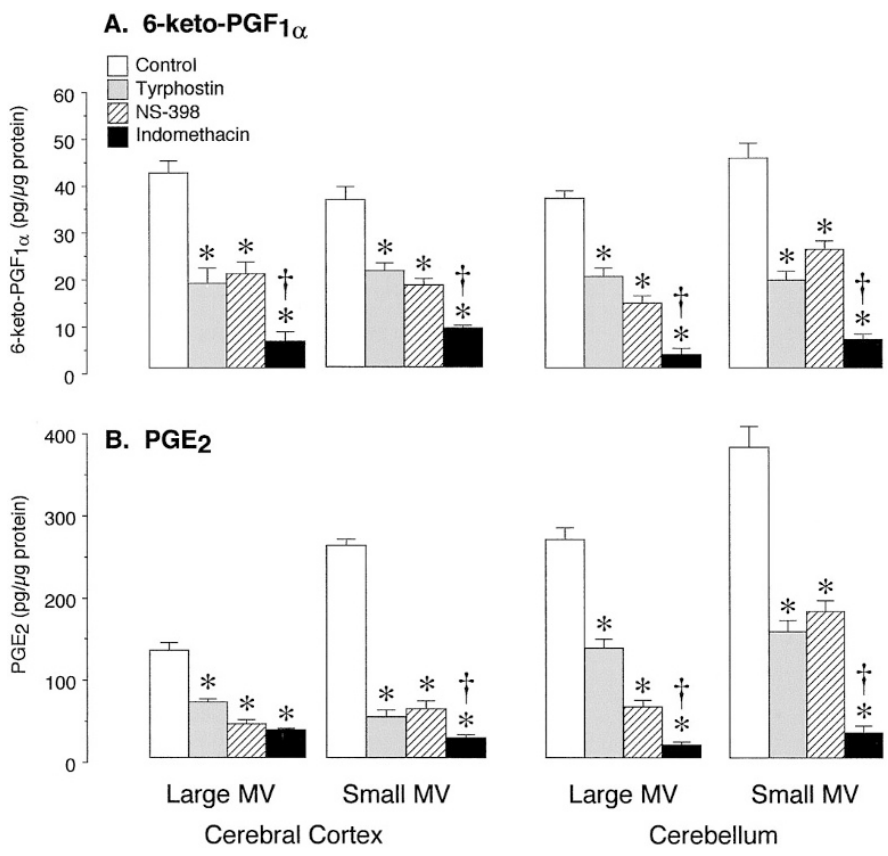

Figure 4. Effects of indomethacin, tyrphostin 25 , and NS-398 on IL-1 $\beta$ stimulated COX activity in endothelial cells from neonatal human brain. Quiescent endothelial cells from large microvessels (Large $M V$ ) and small microvessels (Small $M V$ ) from cerebral cortex and cerebellum (passage 1-2) were incubated with IL-1 $\beta(50 \mathrm{ng} / \mathrm{mL})$ in the starvation media $(0.1 \%$ FBSDMEM) for $17 \mathrm{~h}$. IL-1 $\beta$-stimulated cells were untreated (control) or treated with tyrphostin $25(300 \mu \mathrm{M})$, NS-398 $\left(10^{-4} \mathrm{M}\right)$, or indomethacin $\left(10^{-4} \mathrm{M}\right)$ for $30 \mathrm{~min}$; inhibitors were also included in the incubation medium for determination of COX activity. COX activity was detected as production of 6-keto$\mathrm{PGF}_{1 \alpha}(A)$ and $\mathrm{PGE}_{2}(B)$ from $30 \mu \mathrm{M}$ AA. The experiment was reproduced three times. Data are mean \pm SEM. ${ }^{*} p<0.05$ compared with the control levels. $\dagger p<0.05$ compared with the NS-398 levels. 
stimulated endothelial cells from human neonatal brain, COX-2 substantially contributes to total prostanoid synthesis. No differences were observed between first and second passages of hCMVEC in their responses to the cytokine, NS-398, or tyrphostin 25 (data not shown).

We compared contributions of COX isoforms to total COX activity in hCMVEC under basal and IL- $1 \beta$-stimulated conditions (Fig. 5). COX-1 and COX-2 activities were measured as the NS-398-resistant and NS-398-inhibited components of the total COX activity (as $\mathrm{PGE}_{2}$ and 6-keto- $\mathrm{PGF}_{1 \alpha}$ production from AA), respectively (9). In control neonatal hCMVEC, COX-1 and COX-2 equally contribute to basal $\mathrm{PGE}_{2}$ synthesis in both large and small microvessels from cerebral cortex and cerebellum (Fig. 5). However, it appears that there are certain regional differences in hCMVEC responses to the proinflammatory cytokine. Although COX-2 is the major isoform responsible for increased prostanoid synthesis in IL-1 $\beta$ stimulated neonatal hCMVEC from cerebral cortex, extensive COX-1 activation was observed in cerebellum (Fig. 5). In hCMVEC from cerebellum, IL-1 $\beta$ treatment caused an increase in $\mathrm{COX}-1$-directed $\mathrm{PGE}_{2}$ synthesis 6- to 10-fold, whereas very moderate (if any) COX-1 activation was observed in hCMVEC from cerebral cortex (Fig. 5). Similar data were obtained when COX activity was measured as 6-keto$\mathrm{PGF}_{1 \alpha}$ production from AA under basal and cytokinestimulated conditions (data not shown). Identical changes in $\mathrm{PGE}_{2}$ and 6-keto-PGF ${ }_{1 \alpha}$ production from exogenous AA strongly suggest that IL- $1 \beta$ stimulates COX activity in hCMVEC, although up-regulation of terminal prostanoid synthases cannot be excluded. These data are in concert with our previ-

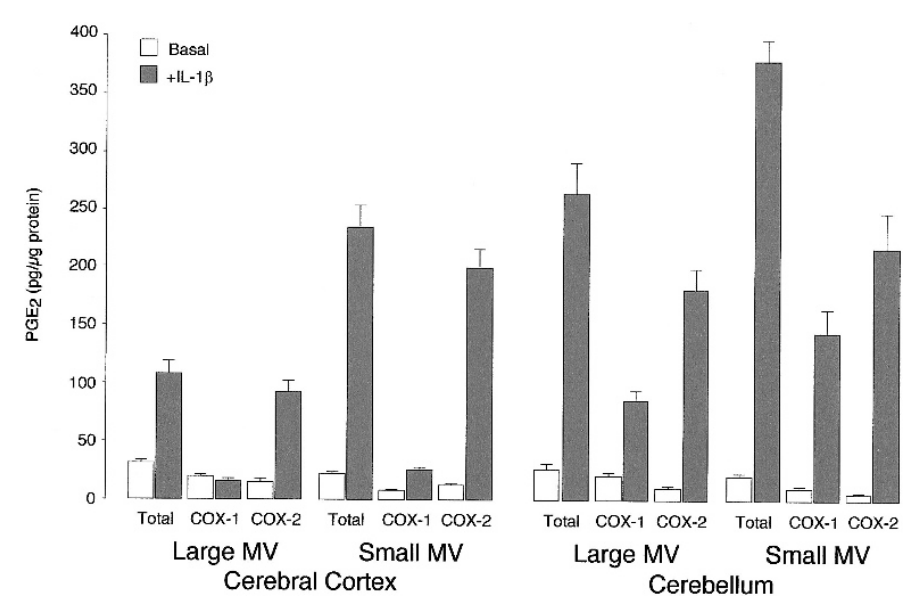

Figure 5. Functional contribution of COX-1 and COX-2 to endothelial $\mathrm{PGE}_{2}$ synthesis in neonatal human brain under basal and IL- $1 \beta$-stimulated conditions. Quiescent endothelial cells from large microvessels (Large $M V$ ) and small microvessels (Small $M V$ ) from cerebral cortex and cerebellum (passage $1-2)$ were exposed to the starvation medium (0.1\% FBS-DMEM) without (basal) or with IL-1 $\beta(50 \mathrm{ng} / \mathrm{mL})$ for $17 \mathrm{~h}$. Cells were exposed to NS-398 $\left(10^{-4} \mathrm{M}\right)$ or indomethacin $\left(10^{-4} \mathrm{M}\right)$ for $30 \mathrm{~min}$; inhibitors were also included in the incubation medium for determination of $\mathrm{COX}$ activity. Indomethacininhibited production of $\mathrm{PGE}_{2}$ from $30 \mu \mathrm{M}$ AA was used as an index of total COX activity. COX-1- and COX-2-directed activities were detected as NS398-resistant and NS-398-inhibited components of total COX activity, respectively. The experiment was reproduced three times. Data are mean \pm SEM. ous findings that IL- $1 \beta$ up-regulates COX-2 expression (mRNA and protein) in human endothelial cells (10).

\section{DISCUSSION}

Knowledge of mechanisms that regulate blood flow through the brain in humans is limited. Although some data are published on cerebral microvascular cells from adult human brain (12-14), no experimental data on human fetal or neonatal brain endothelial cells are available. Endothelium-dependent mechanisms that regulate cerebral blood flow are species-specific and age-dependent (1). In adult rats, mice, rabbits, and cats, NO-dependent mechanisms are predominant, whereas in newborn piglets prostanoids are the major endothelium-derived vasorelaxant factors in cerebral microcirculation $(1,15-17)$. Although data on mechanisms of control of cerebral circulation are growing exponentially in adults, much less knowledge of the mechanisms involved in regulation of the cerebral microcirculation in the perinatal period is available. In pigs, transition from the newborn to juvenile status is accompanied by growing involvement of NO-mediated cerebral vascular responses $(9,18,19)$. Mechanisms involved in control of cerebral circulation in the perinatal period are critically important. Disorders of the cerebral circulation are major causes of morbidity and mortality and can result in life-long disabilities in survivors. With improvements in neonatal medicine, survival of very low birth weight infants is increasing progressively. However, the most frequent impairments in very low birth weight infants are neurologic (20), usually secondary to cerebrovascular complications. Studies in premature human infants suggest a high sensitivity of the cerebral circulation to the COX inhibitor indomethacin (21-23). Indomethacin is widely used in neonatal clinics in treatment of diverse vascular disorders (2, $4,5)$.

Our present and published (10) data demonstrate that both COX-1 and COX-2 are expressed in cerebral microvessels and in nonstimulated neonatal hCMVEC from premature human neonates (22-26 wk gestational age). In neonatal CMVEC, COX-1 is localized in the nuclear envelope, perinuclear zone, and endoplasmic reticulum, whereas COX-2 is mainly an intranuclear resident (10). Although COX-2 protein is immunodetected in the human neonatal cerebral microcirculation (10), the contribution of COX-2 to endothelial prostanoid synthesis in neonates had not been previously established. Our present data are the first to determine COX activity in neonatal hCMVEC. Cultured hCMVEC produce prostanoids from exogenous AA, which is indicative of COX activity. NS-398, the COX-2 specific inhibitor, inhibited 30 to $50 \%$ of total COX activity in hCMVEC from neonatal cerebral cortex and cerebellum, suggesting a significant contribution of COX-2 to basal prostanoid synthesis in human neonatal cerebral microcirculation. We did not find regional or size-related differences in COX activity or its sensitivity to NS-398, which suggests a similar significance of endothelial COX-2 in the function of small and large vessels from both cerebral cortex and cerebellum under basal nonstimulated conditions.

IL-1 is an important mediator of inflammatory responses in the brain. In addition to humoral proinflammatory cytokines, 
human brain endothelial cells also have a capacity to produce IL-1 $\beta$ in response to inflammatory stimuli such as lipopolysaccharide, tumor necrosis factor- $\alpha$, and interferon- $\gamma$ (12). As we have demonstrated previously in human endothelial cells, IL-1 $\beta$ time-dependently induces COX-2 (mRNA and protein) expression (10). However, data on COX activity in cytokinetreated hCMVEC were not available until now. Neonatal hCMVEC from cerebral cortex and cerebellum respond to prolonged $(17 \mathrm{~h})$ treatment with IL-1 $\beta$ by increasing COX activity 5 - to 50 -fold. After prolonged stimulation with IL-1 $\beta, \mathrm{PGE}_{2}$ becomes a major endothelial-derived dilator prostanoid $\left(\mathrm{PGE}_{2}\right.$ to 6-keto-PGF ${ }_{1 \alpha}$ ratio increases up to 10:1 compared with $2: 1$ under basal conditions). It is possible that IL- $1 \beta$ differentially affects the expression of terminal prostanoid synthases, with $\mathrm{PGE}_{2}$ synthase being up-regulated to a greater extent than prostacyclin synthase. We have demonstrated previously that in hCMVEC from cerebral cortex, IL- $1 \beta$ maximally induces COX-2 expression in 12-16 h, and also causes COX-2 relocation from the nucleus to the nuclear envelope and the cytoplasm (10). In this study we demonstrate that up to $80 \%$ of IL- $1 \beta$-induced COX activity can be blocked by NS-398, indicating that COX-2 is the major isoform that accounts for prostanoid synthesis in neonatal hCMVEC during inflammatory conditions. Increased COX-2 activity in response to IL- $1 \beta$ was observed in both small and large microvessels from cerebral cortex and cerebellum.

COX-1-directed activity was also increased in hCMVEC after prolonged stimulation with IL- $1 \beta$. Although COX- 2 is the major COX isoform induced in response to proinflammatory cytokines in a variety of cell types, including human vascular endothelial cells $(6,10)$, COX-1 induction has been also described (24). In hCMVEC from cerebral cortex, COX-1 activation (as NS-398-resistant COX activity) in response to IL-1 $\beta$ was very moderate, if any. Similarly, only moderate COX-1 mRNA up-regulation by IL- $1 \beta$ was observed in human umbilical vein endothelial cells (10). However, in IL-1 $\beta$ stimulated hCMVEC from cerebellum, COX-1 was activated 5- to 10 -fold above the basal level. High COX-1 responsiveness to IL- $1 \beta$ was observed in both large and small microvessels from cerebellum.

The responses of endothelial cells to IL- $1 \beta$ are not limited by COX-2 mRNA and protein induction, but are also influenced by subcellular compartmentalization of the COX-2 protein (10), as well as by modifications of the COX-2 activity (8). In endothelial cells from cerebral microvessels of newborn pigs, COX-2 is posttranslationally activated by protein tyrosine phosphorylation, whereas COX-1 activity is not sensitive to PTK inhibitors (8). Our present data in neonatal hCMVEC from cerebral cortex and cerebellum demonstrate that basal COX activity was rapidly inhibited by tyrphostin 25 , a PTK inhibitor. Tyrphostin 25 also rapidly inhibited COX activity in hCMVEC pretreated with IL- $1 \beta$ to up-regulate COX-2 expression. Inhibitory effects of tyrphostin on endothelial COX activity were observed in small and large vessels from both cerebral cortex and cerebellum, and the extent of the inhibition was comparable to the effect of NS-398.

Taken together, our data indicate that the regulation of endothelial prostanoid synthesis in cerebral microcirculation of human neonates has characteristics similar to the newborn pig brain. In CMVEC from neonatal human and porcine brain, COX-2 is expressed under basal conditions and contributes to basal endothelial prostanoid synthesis in small and large cerebral microvessels from cerebral cortex and cerebellum. COX-2 is transcriptionally up-regulated and posttranslationally activated in response to the proinflammatory cytokine IL- $1 \beta$. COX-2 activity under basal and IL- $1 \beta$-stimulated conditions is rapidly inhibited by tyrphostin, indicating significance of posttranslational activation of COX-2 by tyrosine phosphorylation.

Are the physiologic data from pigs also consistent with available data from humans? The sparse data on contributions of prostanoids and NO to the human newborn and adult cerebral circulations appear to be consistent with greater relative contributions of NO in comparison to prostanoids with postnatal development. For example, an endotheliumdependent, indomethacin-inhibited dilator influence, detected in human infant vertebral arteries in vitro, was not present in adult arteries (25). Further, endothelium-dependent dilation to acetylcholine was inhibited by indomethacin in the infant but by $N \omega$-monomethyl-L-arginine, an NO synthase inhibitor, in the adult (25). These data suggest an age-dependent shift in the primary endothelial-dependent dilator mechanism of the human vertebral artery from prostanoid to NO. Numerous studies in premature human infants suggest a high sensitivity of the cerebral circulation, particularly hypercapnia responsiveness, to the COX inhibitor indomethacin $(21-23,26)$. Data from human infant cerebral arteries in vitro suggest that generation of $\mathrm{NO}$ in response to calcium ionophore is markedly reduced in the human infant compared with newborn lambs (27). In contrast to those of piglets, cerebral arterioles of newborn lambs, whose brains are considerably more mature at birth than those of humans and pigs (28), display NO-dependent vasodilation in response to acetylcholine (unpublished observations) and hypoxia (29). Data on adult humans, as infants, is very limited, but with regard to effects of COX inhibitors, responses are similar to those from juvenile pigs (and adult rats). Thus, indomethacin typically reduces cerebral hyperemia in response to hypercapnia by $50 \%$ or less, much less than in newborns ( 30 , 31). Overall, constitutive expression of COX-2 appears to be a specific characteristic of human tissues. In healthy human volunteers, administration of celecoxib, a COX-2 selective inhibitor, greatly reduced urinary excretion of prostanoids to the same extent as ibuprofen does (32), indicating significant COX-2 contribution to overall prostanoid production in the human body.

Thus, our biochemical data are consistent with physiologic data from piglets in the laboratory and babies in the nursery, suggesting prostanoids and control of cerebral circulation in newborns of these two species are very similar. COX-2 is a major isoform that contributes to endothelial prostanoid synthesis in newborn babies and in piglets under normal physiologic conditions and in response to a proinflammatory cytokine IL-1 $\beta$. Although no data are available on clinical use of COX-2 specific inhibitors in neonatology, preclinical trials on celecoxib effects have been undertaken (33). Considering the major regulatory role of endothelial prostanoids in the cerebral circulation in humans under basal conditions and in response to 
inflammation, careful consideration should be taken regarding potential side effects of the COX-2 inhibitors on blood supply to the brain in premature newborn babies.

Acknowledgments. The authors thank Alex Fedinec for excellent technical support and Danny Morse and Greg Short for helping with preparation of the figures.

\section{REFERENCES}

1. Leffler CW, Armstead WM, Shibata M 1993 Role of eicosanoids in cerebral hemodynamics. In: Phyllis JW (ed) The Regulation of Cerebral Blood Flow. CRC, Boca Raton, FL, pp 297-313

2. Liem KD, Hopman JC, Kollee LA, Oeseburg B 1994 Effects of repeated indomethacin administration on cerebral oxygenation and haemodynamics in preterm infants: combined near spectrophotometry and Doppler ultrasound study. Eur J Pediatr 153:504-509

3. Pourcyrous M 1999 Cerebral hemodynamic measurements in acute versus chronic asphyxia. Clin Perinatol 26:811-828

4. Knight DB 2001 The treatment of patent ductus arteriosus in preterm infants: a review and overview of randomized trials. Semin Neonatol 6:63-73

5. Ment LR, Vohr B, Allan W, Westerveld M, Sparrow SS, Schneider KC, Katz KH Duncan CC, Makuch RW 2000 Outcome of children in the indomethacin intraventricular hemorrhage prevention trial. Pediatrics 105:485-491

6. Smith WL, DeWitt DL, Garavito RM 2000 Cyclooxygenases: structural, cellular, and molecular biology. Annu Rev Biochem 69:145-182

7. Parfenova H, Balabanova L, Leffler CW 1998 Posttranslational regulation of cyclooxygenase in cerebral endothelial cells. Am J Physiol 274:C72-C81

8. Parfenova H, Fedinec A, Leffler CW 1999 Role of tyrosine phosphorylation in the regulation of cerebral vascular tone in newborn pig in vivo. Am J Physiol 276:H185H193

9. Parfenova H, Massie V, Leffler CW 2000 Developmental changes in endotheliumderived vasorelaxant factors in cerebral circulation. Am J Physiol Heart Circ Physiol 278:H780-H788

10. Parfenova H, Parfenov VN, Shlopov BV, Levine V, Falkos S, Poucyrous M, Leffler CW 2001 Dynamics of nuclear localization sites for COX-2 in vascular endothelial cells. Am J Physiol Cell Physiol 281:C166-C178

11. Peri KG, Hardy P, Li DY, Varma DR, Chemtob S 1995 Prostaglandin G/H synthase is a major contributor of brain prostaglandins in the newborn. J Biol Chem 270:24615-24620

12. Corsini E, Dufour A, Ciusani E, Gelati M, Frigerio S, Gritti A, Cajola L, Mancardi GL, Massa G, Salmaggi A 1996 Human brain endothelial cells and astrocytes produce IL-1 $\beta$ but not IL-10. Scand J Immunol 1996 44:506-511

13. Iadecola C, Forster C, Nogawa S, Clark HB, Ross ME 1999 Cyclooxygenase-2 immunoreactivity in the human brain following cerebral ischemia. Acta Neuropathol 98:9-14

14. Stanimirovic D, Shapiro A, Wong J, Hutchison J, Durkin J 1997 The induction of ICAM-1 in human cerebromicrovascular endothelial cells (HCEC) by ischemia-like conditions promotes enhanced neutrophil/HCEC adhesion. J Neuroimmunol 76:193205
15. Dumont I, Hou X, Hardy P, Peri KG, Beauchamp M, Najarian T, Molotchnikoff S, Varma DR, Chemtob S 1999 Developmental regulation of endothelial nitric oxide synthase in cerebral vessels of newborn pig by prostaglandin $E_{2}$. J Pharmacol Exp Ther 291:627-633

16. Li DY, Hardy P, Abran D, Martinez-Bermudez AK, Guerguerian AM, Bhattacharya M, Almazan G, Menezes R, Peri KG, Varma DR, Chemtob S 1997 Key role for cyclooxygenase-2 in $\mathrm{PGE}_{2}$ and $\mathrm{PGF}_{2 \alpha}$ receptor regulation and cerebral blood flow of the newborn. Am J Physiol 273:R1283-R1290

17. Aranda JV, Beharry K, Sasyniuk B, Chemtob S 1993 The role of prostanoids in neonatal cerebral blood flow autoregulation. J Lipid Mediat 6:493-501

18. Zuckerman SL, Armstead WM, Hsu P, Shibata M, Leffler CW 1996 Age dependence of cerebrovascular response mechanisms in domestic pigs. Am J Physiol 271:H535$\mathrm{H} 540$

19. Willis AP, Leffler CW 1999 NO and prostanoids: age dependence of hypercapnia and histamine-induced dilations of pig pial arterioles. Am J Physiol 277:H299-H307

20. Bregman J 1998 Development outcome in very low birthweight infants: current status and future trends. Neonatol Update 45:673-690

21. Cowan F 1986 Indomethacin, patent ductus arteriosus, and cerebral blood flow. J Pediatr 109:341-344

22. Laudignon N, Chemtob S, Bard H, Aranda JV 1988 Effects of indomethacin on cerebral blood flow velocity of premature newborns. Biol Neonate 54:254-262

23. Edwards AD, Wyatt JS, Richardson CE, Potter A, Cope M, Delpy DT, Reynolds EOR 1990 Effects of indomethacin on cerebral hemodynamics in very preterm infants. Lancet 335:1491-1495

24. Jackson BA, Goldstein RH, Roy R, Cozzani M, Taylor L, Polgar P 1993 Effects of transforming growth factor beta and interleukin- $1 \beta$ on expression of cyclooxygenase 1 and 2 and phospholipase $A_{2}$ mRNA in lung fibroblasts and endothelial cells in culture. Biochem Biophys Res Commun 197:1465-1474

25. Charpie JR, Schreur KD, Papadopoulos SM, Webb RC 1994 Endothelium dependency of contractile activity differs in infant and adult vertebral arteries. J Clin Invest 93:1339-1343

26. Lundell BP, Sonesson SE, Cotton RB 1986 Ductus closure in preterm infants: effects on hemodynamics. Acta Paediatr Scand Suppl 329:140-147

27. Pearce WJ, Longo LD 1991 Fetal and newborn cerebral vascular responses and adaptations to hypoxia. Semin Perinatol 15:40-48

28. Tuor UI, Del Bigio MR, Chumas PD 1996 Brain damage due to cerebral hypoxia/ ischemia in the neonate: pathology and pharmacological modification. Cerebrovasc Brain Metab Rev 8:159-193

29. van Bel F, Sola A, Roman C, Rudolph AM 1995 Role of nitric oxide in the regulation of the cerebral circulation in the lamb fetus during normoxia and hypoxia. Biol Neonate 68:200-210

30. Markus HS, Vallance P, Brown MM 1994 Differential effect of three cyclooxygenase inhibitors on human cerebral blood flow velocity and carbon dioxide reactivity. Stroke 25:1760-1764

31. Wennmalm A, Eriksson S, Hagenfeldt L, Law D, Patrono C, Pinca E 1983 Effect of prostaglandin synthesis inhibitors on basal and carbon dioxide-stimulated cerebral blood flow in man. Adv Prostaglandin Thromboxane Leukot Res 12:351-355

32. McAdam BF, Catella-Lawson F, Mardini IA,.Kapoor S, Lawson JA, FitzGerald GA 1999 Systemic biosynthesis of prostacyclin by cyclooxygenase (COX)-2: the human pharmacology of a selective inhibitor of COX-2. Proc Natl Acad Sci USA 96:272277

33. Sakai M, Tanebe K, Sasaki Y, Momma K, Yoneda S, Saito S 2001 Evaluation of the tocolytic effect of a selective cycooxygenase-2 inhibitor in a mouse model of lipopolysaccharide-induced preterm delivery. Mol Hum Reprod 7:595-602 